\title{
Explaining Foreign Direct Investments in Gujarat: A Study based on an Opinion Survey of Persons Involved in the Foreign Direct Investment Process \\ Sebastian Morris
}

WP No. 2005/02/01

The main objective of the working paper series of the IIMA is to help faculty members to test out their research findings at the pre-publication stage

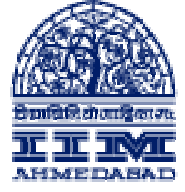

Indian Institute of Management

Ahmedabad

INDIA 


\title{
Explaining Foreign Direct Investments in Gujarat: A Study based on an Opinion Survey of Persons Involved in the Foreign Direct Investment Process ${ }^{1}$
}

\author{
Sebastian Morris ${ }^{2}$
}

Abstract

Gujarat has attracted more foreign direct investment (FDI) than what its GDP size alone would suggest. But relative to its peer states (especially Tamilnadu, Delhi, Maharashtra and Karnataka, and possibly Andhra Pradesh) it has fallen short significantly. The above findings which we made in an earlier study are further confirmed through a survey of opinions and views of CEOs and others intimately concerned with the foreign investment decision process. The survey also brought out the crucial importance of infrastructure, and the quality of governance. Interestingly most of the problems are capable of being corrected through appropriate government action. The intrinsic exploitable advantages of the state remain large.

Electricity supply - its poor quality, inadequacy and high price; the adverse law and order situation including the impact of the communal strife and riots and the perception of biases in the implementation of law have been important in adversely affecting FDI.

The large comparative advantage of the state in industry and manufacturing implies that the states' future is intimately dependent upon the growth of manufacturing in India. Success therefore involves coordination with the central government, because many of the difficulties in moving forward and in evolving into modern industries faced by Gujarat's existing manufacturing involve policy infirmities at the central Imacroeconomic level. Important among these are the 'inverted tariff structures' that many of Gujarat's manufacturing, especially those in the small and medium scale

\footnotetext{
${ }^{1}$ The author thanks the Government of Gujarat, and Prof. Ravindra Dholakia for the support extended. An earlier version of this paper was submitted to the Govt. of Gujarat. The same was also presented in the "Workshop on Select Aspects of Development of Gujarat", Indian Institute of Management, Ahmedabad, on September $24^{\text {th }} 2004$.

2 email: $\underline{\text { morris@iimahd.ernet.in }}$
} 
industries, face and the tame pricing of the Indian rupee, in contrast to East Asian countries' strategy of undervaluing their currencies.

There is much that Gujarat can do to attract the new manufacturing and service industries (offshore industries of a wide variety, IT and biotechnology industries). Besides the improvement of Governance especially with regard to control over communal strife, it would need to improve the quality of life in cities and overcome the infrastructural constraints especially with regard to education and availability of technical skills. If Ahmedabad its principal city, can improve its ranking in the hierarchy of central places, Gujarat could successfully attract a lot more FDI, and other non-equity forms of collaboration in the new manufacturing and service industries.

\section{REVIEW OF DEVELOPMENTS IN GUJARAT}

The Manufacturing Sector is the Key to Gujarat

Gujarat has been an important destination for investments especially those that are industrially oriented and in the chemical, petrochemical, dyes and pharmaceutical sectors. It also has a large industrial base, and is second only to Maharashtra in the level of industrialisation. Gujarat has prided itself in the investments that it is able to attract, and has typically ranked first or second in terms of the quantum of investment that it has been able to attract. Its industrial growth has been by a wide margin the highest in the country over the high growth period of the eighties, In the nineties up until 1995-96 it grew most rapidly after the period of stabilisation of the Indian economy in 1991-92 and 1992-93. But since then its growth has been moderate. The veering of national level macroeconomic, trade and investment policies away from industrial and manufacturing orientation, which has prematurely lowered the growth rate of the manufacturing sector across India, has had an amplified effect on Gujarat since its natural competitiveness is in manufacturing especially of the resource (investment) and land intensive variety.

\section{SME Policy Constraints Hurt Gujarat}

Additionally much of Gujarat's small and medium industries which had grown rapidly in the eighties, even more rapidly than the large industries, slowed down considerably in the nineties after 1995-96 and some important industries may not be able to recover if the current policy orientation of the 
government continues ${ }^{3}$. Essentially several factors have adversely impinged upon the growth of small and medium industries. Important among these have been the triple bind of restrictive credit to small firms (Morris, S. 2001), the slower growth in demand given the conservative monetary and fiscal policies since 1997-98, and the appreciation in the real value of the rupee (Morris, S, 1997). The latter feature has adversely affected the competitiveness of many industrial clusters that are still labour intensive and craft based - gems and jewellery, clocks and plastic small crafts, ceramics, diesel engines, brass parts, handicrafts and ship cutting. Additionally the inverted tariff structure in discriminating manufacturing has also taken its toll on Gujarat's manufacturing.

\section{Fiscal Incentives for Location}

The only positive aspect in the secondary sector since 1997-98 for Gujarat has been the investments in infrastructure especially those related to ports and now in gas and oil pipelines. Here the incontestable natural advantages of the state have insulated it from adverse central government polices. Even here the regulatory and policy risks especially with regard to gas, but also in oil, the de facto shelving of the promised exit from the Administered Price Mechanism, the large burden of taxes on the oil sector have not allowed Gujarat to build on this sector as much as it could have.

Policies and practices of Gujarat too have stood in the way of achieving high growth. Thus the sudden exit from the locational incentives especially for medium and small industries which had been pushed earlier to inappropriate locations have had large impact.

\section{Supreme Court Activism}

The tolerance of pollution by the government and the Gujarat Pollution Control Board (GPCB) could not have continued for ever since, it invited strong reaction from the Supreme Court. Many industries had to be closed down, or operated illegally, or incur large costs to operate in the wake of the Supreme Court's judgements and the rising public consciousness against pollution. Some are "allowed" to operate illegally. Appropriate and more

${ }^{3}$ Examples would be the shipbuilding industry based in Alang, the diesel engine cluster, and much of the brass parts clusters, all of which are dominated by small and medium industries. 
concentrated locations had they been permitted earlier would have allowed better adjustment of such industries in the nineties. The continued unchecked pollution in many industrial locations, typically in the outskirts of cities, make these locations less attractive to other clean industries that include service industries, which have shown much dynamism elsewhere in the country.

\section{Expensive Power for Industry}

Additionally starting from the nineties the power situation in Gujarat has deteriorated, and power costs are high relative to neighbouring states. Similarly, state taxes too are high. Such high tax policies in an era of high growth of manufacturing and industries (as in the first half of the nineties) were not entirely dysfunctional especially if the government could use the resources so generated to finance supportive infrastructural investments, which it did in ports roads and irrigation sectors. But in the late nineties with the slow down in the manufacturing sector, and much competition among states to attract businesses, the policy of higher local tax rates and higher energy taxes and costs have adversely affected the state.

\section{THE PROBLEM OF FDI}

In an absolute sense Gujarat has attracted much FDI certainly incomparably more than its share of population or GDP. When the comparison is with the country as a whole, it has done better. But relative to Maharashtra, Delhi, Karnataka and possibly even Andhra Pradesh, and adjusted for its economic size it has attracted much less FDI. Equally importantly the number of cases of FDI that Gujarat has been able to attract is much smaller than what its volume of FDI would indicate. In other words few of the many firms that invested in India following the open door policies have come to Gujarat but have preferred the other mentioned states.

\section{Central Policies and FDI}

A large part of the explanation lies in the industrial structure of the state, which is heavily oriented to infrastructure, and chemical and allied industries besides small scale manufacturing in clusters, which have been slow to shift technologies. Thus the problem of FDI if we were to address it as such is simply that Gujarat has an industrial structure that is not prone to foreign direct investments given the current state of central government 
policy. Gas distribution and transmission until recently was subject to major policy and regulatory uncertainty. Power, especially that destined for cross regional use, continues to be subject to regulatory and policy uncertainty. The large numbers of small and medium industries in very many sectors lack the growth opportunities and challenges especially in high growth of their exports which could then have usefully benefited from the infusion of foreign capital and technology. (Morris, S., 2001; Morris, S., 1997). Similarly the policy of keeping reservation for small scale industries alive in the face of open imports, and not allowing FDI and large firm investments in the equity and capital of small firms, have led to their stagnation, and reduced ability to respond to the challenges of a competitive economy. These restrictions in hurting manufacturing and small firm transformation particularly in their development of inter firm linkages would have hurt Gujarat given its significant dependence on small scale manufacturing which during the eighties and the seventies were among its most dynamic sectors, and today urgently need to transform - diesel engines manufacturing, brass parts, ceramic industries, plastic goods, chemicals, drugs and pharmaceuticals. (Morris, S. and Rakesh Basant, 2004).

\section{Education and Soft Infrastructure}

The contrast of Gujarat with other states is worth mentioning. Maharashtra, Delhi and Tamilnadu are expected to do well in FDI for the reason that they house the original metropolitan cities of India. The reasons for the same have been argued before. ${ }^{4}$ But the contrast with Karnataka and Andhra Pradesh, more so the former, is most worrying. Although both Karnataka and AP were second order states, perhaps of rank even lower than Gujarat, they have been able to attract much FDI. This is because software and related industries do demand a certain kind of location - largish cites with good living spaces, access to trained and skilled manpower and availability of good English language skills. Such industries also depend significantly on agglomeration economies that arise from their need for the above conditions and facilities, the large spill over effects of such industries, and their interdependence upon each other.Therefore, such industries once established would favour the states where they are clustered and discriminate those states where the clusters have not as yet reached critical (take off) levels.

${ }^{4}$ In part I of the larger study on FDI in Gujarat, reported in Morris, S. (2004). 
Is Gujarat's a case of being a late starter in so far as these industries are concerned? This is most unlikely since Gujarat was one of the first to pursue an electronics cluster in Gandhinagar and Ahmedabad. But its hardware oriented firms died or migrated out to other places as these grew into clusters. The relative decline of much of IT related manufacturing was abetted by the import tariff problems including the tariff inversion for activities in which the country had potentially realisable comparative advantage. The extreme undervaluation of the currencies of East Asian countries and China, and macroeconomic management in India which did not recognise this phenomenon, not to speak of attempting to follow the East Asian countries (Morris, S. 1997) was perhaps most crucial Despite the best efforts of the state such as promoting an IT park it has not been successful in attracting IT industries whether hardware or software.

\section{Setback Despite Early Start}

The industries associated with hardware, and software even more than these (contract engineering and R\&D, contract programming, now offshore business operations, offshoring a wide variety of services) are intrinsically linked to foreign businesses through both direct investments and non-equity forms, more than other industries are. The higher propensity of foreign investments in states with a larger proportion of these industries is, therefore, not surprising. It is possible to 'explain' in a large measure, the relatively poor performance of Gujarat in FDI in terms of its industry mix or structure. But this only shifts the question. We would then ask why Gujarat was not able to attract the new service and technology intensive industries that Karnataka and AP were able to? Initial successes in both these industries in Gujarat came up against skill constraints locally, and perhaps even more the pull of more hospitable locations acted against Gujarat. The state has not been able to correct either the inadequate endowment of skills and facilities related to training and education, nor the pull of 'better' locations. Therefore, there are casual factors that go beyond industrial promotion or extension, which need to be uncovered. This is of course a broader issue than FDI or industrial development but obviously the FDI issue cannot be understood in isolation.

Gujarat can ill afford missing out the bus of IT and related industries, not only because these industries are dynamic but also because they are 
associated with biotech industries as they evolve, which could have been Gujarat's natural extension given its base in chemicals and pharmaceuticals. These industries are likely to be much more foreign in connectedness if not in ownership. So an inability to attract FDI broods ill for the state's future. As argued before, unlike in the past because of the competitiveness among foreign enterprises (Morris, S., 2004), the benefits to be had from FDI are large. And in any case in a federal context it makes sense for Gujarat as for any state to maximise all the investments, especially of the high tech clean variety which also have positive external effects .

\section{GUJARAT'S FDI PERFORMANCE}

The important question is 'how much of the difference between Gujarat and leading states on FDI performance is explainable by the industry structure and how much on account of the factors intrinsic to the state and in attracting foreign investment?'. This is important because in case the "Gujarat (regional) factor" adjusted for industry structure differences is still significant then Gujarat needs to worry about its policies, practices and other actionable determinants in two senses. Firstly it has to be concerned with attracting industries and activities that are intrinsically rich in FDI electricity generation, $\mathrm{mfg}$ of chemicals, $\mathrm{mfg}$ of motor vehicles, computer software services, telecom services, and other services related to telecom, transportation storage and distribution especially related to air and shipping in a quantity (foreign equity share capital) sense, and chemicals, electronic equipment and parts, motor vehicles, business services and consultancy, computer services and telecom related services in the sense of the numbers of the enterprises involved ${ }^{5}$. [Except chemicals and telecom services, Gujarat has not been able to attract the other industries in any significant manner]. Secondly, if factors intricate to attracting FDI too have been adverse, the correction of such factors to the extent they are actionable is also important.

We regressed the foreign equity destined to states in each of the forty one industry groups on industry dummies, state SDP during the year 1993, growth in GDP between 1993 and 1996, and state dummies for Gujarat, Maharashtra, Karnataka, Tamilnadu, Delhi and Andhra Pradesh, with reference to the rest of India. The results are reported in Table 1. Similar regression was carried out but with the no of technical and technical cum

${ }^{5}$ These are given the current policy regime of the country and the situation as of tradability of goods and services. The list would change to the future. 
financial collaboration agreements as the dependent variable. The results are reported in Table 2.

\section{Not a Preferred Destination}

Observe from table 1 that with respect to the rest of India, excluding the chosen states Gujarat is not significantly different, whereas the other peer states (other than AP) are all significantly different and positive, in the amount of destined equity share capital. Note also that Delhi and Maharashtra which house the two principal metros have very large coefficients implying that they are the preferred destinations for FDI, even after adjusting for industry effects. AP is barely significant. But the real difference and lead is that of Karnataka, which unlike Delhi or Maharashtra is only a second order state.

The numbers regression (see table 2) further confirm the picture bringing out the lead of Delhi and Maharashtra especially the latter. Gujarat is again barely different from the rest of India. Thus the conclusion is inevitable that even adjusting for the industry effects, Gujarat has not been able to attract FDI any better than the rest of India (but excluding the states AP, Karnataka, Maharashtra, and Delhi, Tamilnadu and Gujarat itself), whereas its peer states have done significantly better.

What factors underlie the relatively poor performance of Gujarat? The obvious 'practical answer' that summarises our discussion is that in the first instance Gujarat was unable to sufficiently attract the industries that typically involve much foreign direct investments or technology. Part of the reason for the same is that its industrial base, consisting of capital intensive and resource using industries, had few such industries to start with. But even taking into account its industry structure Gujarat has done no better.

\section{SURVEY OF DECISION MAKERS}

To operationalise the above question in a way that allows us to understand the problem and lead to actionable solutions for policy makers, we carried out a survey among opinion leaders and decision makers who have much to do with the foreign investment process of firms.

Recognising that opinions about countries regions etc among decision makers are shared, the task of uncovering the opinions and experiences of 
investment in the regions of India was expected to be carried out through a 'small sample' survey since low variance is to be expected, which could be taken advantage of. Thus a response of the order of about 70 persons was thought to be adequate enough. Hence the questionnaire was sent to about 750 persons intimately involved in decision making. Rather than relate the responses of an individual to the particular decisions that he may have been involved in, his views and experiences were considered more generally, except when the responses obviously pertain to a specific characteristic or need of the industry. This is because as said before there is much that is shared among managers and decision makers. Media reports especially those in the financial press, also contribute to the moulding of opinion.

Only one aspect of an opinion or behaviour that shows bandwagon effects, is its truth. And direct investment as much as stock market behaviour, the validity of an opinion or view arises (at least in the short run) as much as from its popularity as its intrinsic truth. This is not to say that decision makers or stock market players hold opinion that has no truth or little truth. The point is that the truth is never fully known, and while the error of opinion and view is corrected there are long periods over which the held opinion provides the basis for action. Thus for the purpose of policy makers it is primarily necessary to know the opinion and view even though the task of correcting the error in them (assuming for the moment that such is the case) may be very difficult. The option available to the policy maker is to work on the tangibles such as those pertaining to infrastructure, governance and leave matters such as those arising out of attitudes, to slowly change on their own . The latter can also happen suddenly and in a gestalt like manner because information and experience about good governance (even if less than bad experiences) tends to be carried and discussed, and once the changed opinion reaches a critical level, then the new opinion can spread like wild fire. Similarly adverse opinion based on the behaviour of the administration in a few situations and on particular acts of the government can through gestalt processes become widely held public opinion.

Following our initial discussions with foreign investors, developers and financiers and our understanding of the foreign direct investment process based on Hymer (1971) and Aharoni (1967) as discussed in part I (Morris, S., 2004), the city of office operations of the foreign investor the characteristics, services and functions the city offers were a priori recognised as being important. We hoped that the same would also be confirmed by the survey. 
Other factors that were expected to influence the choice of foreign investors were the many state level factors, besides of course the factors specific to particular industries, that is factors like endowment of raw materials. [Thus an investment in a copper mine can hardly be expected to take place where there is no copper ore]. Since these are specific and well understood, we kept out such factors and had only a few items like nearness to raw materials with the intention of gauging the relative importance of the many factors of a general nature, in relation to that of specific factors.

Since the questionnaire was to be administered among top managers and decision makers, it was absolutely necessary to keep the questionnaire short enough to enable the respondent to complete the same without much effort and in less than 15 minutes. The fact that the survey was being carried out for academic purposes and by an academic institution, with a view to share the findings with government to improve matters helped in eliciting genuine responses. We received over a 150 responses and a random sample of 70 were selected from about 140 usable responses. The remaining were analysed on key responses to verify the veracity of the schedule.

The questionnaire was sent to all chief executives/officers (CEOs), fund managers, executive directors on the board especially finance directors, chief finance officers (CFOs) of multinational corporations (MNCs) in India, besides financial institutions, developers. Lists were obtained from embassies of foreign countries with companies operating in India, the PROWESS Database of the CMIE, and an assorted list of MNCs obtained from a commercial vendor. The lists were re-checked to eliminate the common entries and checked manually to correct some of the residual errors wherever possible, to give a list of about 750 persons. It was felt necessary that the questionnaire be sent in the name of the respondents and not merely by the name of the company or organisation.

We wanted to be sure that the unfettered and frank opinion and view of important individuals without constraining them by drawing a necessary link with their companies. When individuals are asked to respond 'officially; it is well known that their responses cannot be entirely frank. The utmost confidentiality with regard to their response was promised and it was necessary to communicate this effectively. Equally importantly since individuals move across organisations and because the decision-making individuals form in many ways a 'public' with their own language, culture and opinion, it was this 'special public' rather than an individual 
corporation that was to be usefully understood. Variance of opinion within this group was crucial to the survey design but as mentioned before we did not think it would be large enough to justify a 'large' sample survey, which was amply confirmed.

On the other hand we expected much variation across groups of businesses classified as local business with roots in the local politics and being confined to the local economy, regional businesses, and national and international businesses. Since the survey was restricted to international investors, the variation expected was not large.

Over half of the respondents were CEOs, and the remaining Fund Managers, CFOs, and executive directors on the boards of companies. The questionnaire was so designed as to first elicit the free and unprompted responses. Thus the first substantial question asked the respondent to rate the states according to their FDI performance, and relative to each other. The next question which was open ended asked for the important explanatory factors that underlie Gujarat's FDI performance. Only then did we ask for the rating of the factors that influence the locational choices breaking up the factors into those related to the city (head office, location of service industries and activities) and the state (additionally location of plant, facilities, mining operations etc). The questionnaire ended with eliciting suggestions/views on how Gujarat could enhance the quantum of inward FDI. As a cross check we expected a patternal similarity between the responses to the explanatory factors and to the questions on what Gujarat could do. This was amply confirmed.

\section{POTENTIAL AND ACHIEVEMENT IN ATTRACTING FDI}

As expected Maharashtra scored highest in both the potential and the performance or achievement of FDI (see Table 3). This is very much in keeping with the objective data. We kept out Delhi, because being a citystate its inclusion would have caused some confusion in the relative rating. We kept some well known not so well performing states like UP, Orissa to draw out the relative performance of Gujarat with respect to its peers. Tables 3 and 4 and 5 bring out the details.

To guard against the possibility that the intrinsic variation of individual respondents could have affected the results we recomputed the average achievement and potential of the states after standardising the scores of the 
respondents with mean zero and variance 1 . The mean of the standardised scores for the states is reported in table 4.

Observe that the standard deviation is rather small relative to the mean of the potential. Without standardising the scores the mean potential of the states Maharashtra, Gujarat, Tamilnadu and AP was rated high with Maharashtra a notch higher than the rest. The other three viz UP, WB and Orissa were in a different much lower category. On performance or achievement of FDI though, Gujarat scores much les. Therefore Gujarat stands out as a distinct underachiever relative to its peers. This is revealed by the ratio of its achievement to its potential which was distinctly lower than that of its peers and in the same class as UP WB and Orissa. Table 4 further confirms that the conclusions made on the basis of table 3 remains robust. Gujarat has significantly underachieved relative to its potential in the view of the respondent set.

Responses to questions (6) and (7) further confirm that respondents have understood fully the question (5) to distinguish between the potential and the achievement and to see the achievement relative to the potential. See tables 6 and 7.

The direct responses to question s (6) and (7) are better than $85 \%$ predicted by the detailed response to question (5), thus validating the finding that Gujarat relative to its peers has been underperforming in attracting FDI. It has also underperformed in FDI relative to its potential, given the expectations of the responding group.

\section{EXPLAINING GUJARAT'S PERFORMANCE}

Table 8 brings out the 'freely' stated responses that explain the relative performance of Gujarat. We expect that Gujarat has been on a factor when the same is mentioned as an issue, since a predominantly large majority have rated Gujarat to have underperformed. Respondents have brought out many issues. Appendix 1 gives a complete listing of the statements. Here we have grouped the same into those pertaining to economic governance and decision making, law and order, availability and prices of factors of production, living conditions in the city including such things as infrastructure related to living in the city etc. See table 8. Observe that infrastructural constraints have been the biggest bottleneck in Gujarat's underperformance. Next has been law and order related problems especially 
those related to communal riots, besides economic governance and decision making. The latter two are essentially governance categories therefore pointing to serious problems, as perceived by those involved in the foreign investment decision process. The infrastructural inadequacy is largely on account of power which is well known to be highly priced, and quite erratic in supply especially for industrial users.

Living conditions too have scored rather high pointing to much scope for improvement therein. A tabulation of these issues is given in Appendix 2 bringing them to standard categories and groups, and in which we have recognised the tenor of the response. In this finer categorisation we see that infrastructural problems loomed largest followed by law and order problems, including the fact of the riots and the communal situation. The image of the state being negative [despite the reality being otherwise presumably in the view of the respondent] is also important, as also governance. Other responses further elaborate the same pattern. The inadequate (quality) educational facilities are also mentioned 6 times which is quite remarkable. So also are specific remarks on the weak English language skills among potential employees.

As many as 58 out of the 74 respondents agreed that low achievement of a state on FDI is undesirable from the point of view of its economic

development. What is interesting is that the opinion is not without a caveat, despite the "consensus" in the mass media that that the more the FDI the better it is for the country /region. The answer to the second question too is interesting. Both responses confirm that our respondents constitute a group that is appreciative of the possible dysfunctionalities of FDI. We have already argued that a part of the FDI in India since 1993 being driven by the fischer-open and not because of any intrinsic advantage (Basant, R. and Morris, S. (2002); Rosario, Shirley (1998)). Thus the contingent response on the desirability of FDI, points to a recognition of such aspects as its possible dysfunctionality in displacing domestic capital.

\section{DETERMINANTS OF THE LOCATIONAL DECISION}

\section{City Level Factors}

We tabulate the ratings of the city level factors most of which pertain to living conditions (see table 1). Observe that safety, freedom from crime, law and order in the city score above all other factors. Many of those who rated 
high on this factor also mentioned the communal and riot related law and order problems. It is not surprising though that nearly all the top rated factors relate to what we may call basic conditions for any business for existence. As such these are hygiene factors. This is reflective of the fact that Indian cities offer poor living conditions and facilities even by the standards of LDCs. The East Asian countries have incomparably better cities. The physical infrastructure is good in much of Latin America and even in some cities in Africa, other social problems apart. FDI in India has nevertheless been buoyant due to the economic determinants which have been strong enough to counteract the negative aspect of its cities. It is only in the super metros where the large size and a certain evolution allow for the existence of spaces (even if limited), where 'hygiene' factors are not an issue. Lack of reliable power is a punishment that most Indian cities cannot avoid, which Ahmedabad and Bombay are free of. This for Ahmedabad should have been an important selling point if service industries could have located in the areas where the supply is reliable and good.

\section{Soft Infrastructure and Freedom from Pollution}

Pollution levels are very high in Ahmedabad, and certainly far in excess of what the statistics report. ${ }^{6}$ If we run through the top 9 factors then barring the riots and communal strife, the first factor should have been positive for Ahmedabad, Baroda and Gujarat's principal cities. Thus the direct and indirect affects of the communal riots have been adverse. Similarly, reliability of electricity which is a positive for Ahmedabad, can be extended to the entire urban agglomeration of the city, nearby satellite town and rural areas. Such extension would most certainly remove an important negative factor. Health care facilities are improving even though they are well below those of even smaller cities elsewhere. Another category viz quality of life which captures many aspects, but essentially arises out of the total effect of good physical and social infrastructure and local cultural resources is also mentioned as an adverse factor. Hotels are improving but quality of schooling continues to be remarkably poor in Gujarat. ${ }^{7}$

\footnotetext{
${ }^{6}$ Reported statistics pertain to particulate matter, NOXs and SOXs, whereas the real problem is the large amount of heterocyclical and other carcinogenic compounds, and $\mathrm{CO}$ released due to the use of fuels adulterated with benzene, solvent and kerosene, which is rampant in Ahmedabad and more widely in Gujarat. 7 The relative underachievement of high school going children is indicated by the fact that typically the top rankers from Gujarat in the All India Engineering
} 
The above factors do not change merely by better information or communication campaigns, but would require basic changes on the ground especially at the level of cities, their administration, and the support to cities from the state government and administration. The 'fancy facilities', the lack of which in Gujarat's cities is often alluded to, for their limited capacity to attract global businesses are not very important. Interestingly the high ranked factors here are all actionable - health care, drinking water (already on its mend), education and cleaner cities.

\section{State Level Factors}

Again quickness of decision making, law and order including the freedom from communal disturbances and riots, unbiased application of local laws, appropriate politics i.e. governance and decision making aspects have been highlighted most at the state level as being relevant in the locational choices of foreign direct investors. Others important are power quality and its price, and road or rail infrastructure, water availability and manpower and skills availability. Closeness to raw materials while of overriding importance to the particular industry that is dependent upon raw materials (raw material intensive industry) is less important generally. Emphasis on pollution control is less important. Subsidies are not of importance in this collective response. See table 11 for a complete listing sorted in order of the mean of the scores. The gaps in the standardised scores are of some meaning. Thus "availability of electricity" 0.91 and "little or no communal and social disturbances" have been rated very high by investors. These are undoubtedly the most important factors in the context of the country today. And they are eminently actionable. Next in importance is "no serious law and order problems" which is also actionable. The latter two also pertain to the core aspects of government functioning, Governments cannot absolve themselves of these tasks.

"Little or no militancy/Actions of labour unions" is also important, but is not directly actionable by governments if the region has had a particular history of labour and union behaviour. In this regard states like West Bengal and Kerala despite their governments making serious efforts to correct the hangover of the past find the task difficult.

Entrance Examination would not rank around $20^{\text {th }}$ in the listing for the country as whole, not even in the hundredth but only in the thousandth! 
"Existence of single window", another way of expressing the demand for quick and coordinated approvals and clearances, is at least in part actionable. Even in the hey days of the "license raj" a state like Maharashtra through the setting of the State Investment Corporation of Maharashtra (SICOM), and its effective functioning was able to draw to the state a large share of the licenses for investment awarded to private parties. Specially recruited SICOM liaison officers then would regularly pursue investors even to the point of securing the school admissions of investors children! One of the reasons why SICOM was able to function better than its many imitators was its professionalism and incentive structures within which were not at dissonance with performance ${ }^{8}$.

Today many options are available to state governments including PPPs in industrial promotion and extension, and the associated winding up purely government bodies with agenda that are similar. Gujarat has had a reputation for speedy approvals and clearances at the state level, and therefore with some re-working this should become a major selling point. The point to be recognised here is that many other states have caught up with Gujarat and Maharashtra in speediness of clearances and approvals, so that this has become a 'hygiene' factor for it peers. What merits study is if there are specific problems that smallish IT and technology entrepreneurs could face. Such entrepreneurs and investors as also those that operate on the principle of "no compromise on values"9 (WIPRO, Infosys, TCS, and many others in the IT and related industries), may well have faced difficulties, since government decision making, "uniform application of laws" etc have been mentioned in the free wheeling responses to the question on factors that explain Gujarat's relative performance. It is easy to

\footnotetext{
${ }^{8}$ This was quite a departure from that typical of most departments, and public enterprises when charged with complex tasks.

${ }^{9}$ One, perhaps minor reason, but nevertheless worth mentioning in this context, is that without a adherence to basic values it would be difficult to get work out of IT workers in software development and in creative functions. Typically they also have in work in groups and teams. This is because much of the output of such workers is an 'experience good' and time at work which alone is measurable is no indication of the actual ex-post realized output nor of its quality. Typically such tasks are not performed on job time. There has to be much trust and reliance on each others work which cannot come without values. And it is difficult to separate the values of the work place from the market place.
} 
imagine that such entrepreneurs would not have the knack to wade through the typical corridors of power.

\section{Skills and Manpower Worries}

"Availability of manpower" is a substantial negative for Gujarat, if one goes by the references in the open-ended responses discussed earlier. This has been widely commented upon both within and outside government, but not much has happened to correct the problem. Table 12 brings out the large quantitative deficiencies in technical education in the state of Gujarat. Given Gujarat's lead in industrialisation, its investments in technical education (by government if investments by charitable organisations and the society as such has been lacking) should have been closer to the levels in Maharashtra and Tamilnadu. When it is recognised that Gujarat has a much larger proportion of its workforce in non-agriculture and has the highest proportion of GDP arising from the secondary sector (37\%) in relation to the all India average of under $25 \%$, the inadequacy of the quantum of technical education is quite obvious and beyond the least doubt. While the case of Delhi could be attributed to its status as a city-state, that of Karnataka and Tamilnadu are interesting. Herein private enterprise was not averse to investments in education, despite the delayed (but steady) return possibilities. But economic and administrative factors in the form of support to such private institutions and appropriate control mechanisms put in place by the government and having a modicum of incentive compatibilty, would have also played their roles. Indeed this is one area where the Gujarat government could announce an appropriate framework for private finance initiatives (PFIs), subsidisation and quality standards.

"Quality and connectivity of road networks", physical infrastructure in general are aspects that would be most positive for Gujarat despite the substantial negation of the value created by the exceptionally poor management of traffic especially in the cities and in the areas immediately surrounding cities $^{10}$. Land too is a positive in the case of Gujarat since few states (AP, Orissa) could compete with Gujarat in the ability to allocate land to industries.

${ }^{10}$ Based on the author's extensive driving and travel experience in Gujarat. 


\section{SUGGESTIONS TO ATTRACT MORE FDI?}

The suggestions made by the respondents on what Gujarat can do were expected to cover the aspects /issues that were rated to be important in the "open-ended" question and in their structured response on the determinants of FDI with a high degree of patternal similarity. This is indeed the case. Table 13 below groups the open-ended responses on what Gujarat can do, into broad functional categories. The similarity with table 8 may be noted.

Again most of the improvements suggested and the high scoring ones pertain to actionable categories, especially the first four. The issue of governance (related to core government functions including law and order) ranks only fourth whereas the issue as a determinant was given much greater importance. This is easily understood since some respondents (13) in their suggestions on "law and order /communal strife" saw the problem as also one of correcting the "image of the state" which was perhaps being misperceived. In other words while they see social harmony as being important they view that the image of the state may have been tarnished and hence requiring corrective action. The situation in our view though is not directly actionable, except through future actions and management of communal situations in such a way that there is no scope for misperception. Mere media management beyond a point is of no consequence since there is the issue of credibility in all such situations.

In Appendix 3 we have listed the responses of those who chose to respond to the section open ended suggestions on what Gujarat can do to enhance FDI inflows. They bring out broadly the same concerns that are revealed in Appendix 1 which lists out the reasons for the performance of Gujarat on FDI. Appendix 4 which tabulates these in a more detailed manner than in table 13 is revealing.

In the narrower grouping the action options are to improve infrastructure (despite Gujarat being better than average and perhaps as good as its peer states) especially power supply quality and price to industry, governance related to law and order and the control of communal disturbances including riots, decision making related to investment approval and clearances. It is interesting that English language skills have been specially spelled out, as also prohibition. The latter of course is a choice that has to be made on the basis of aspirations of the people and goes beyond FDI or for that matter even investment. But English language skills are known to be 
inadequate in Gujarat and needs some discussion. Many states of India including West Bengal, Uttar Pradesh and Maharashtra discouraged instruction in English arising out the need to promote the national language and the mother tongue. But this was only partial since the elites in these states could continue to access English education. Private sector white collar, and highly paid blue collar jobs hardly existed without English language skills even in the period of closed door development, and in the days of heightened language 'chauvinism'. And the denial /discouragement of capacity to impart English language skills only heightened the 'elitist' aspect of those with proficiency in the language. What should have merely been an excellent medium of communication between India' peoples and an entry (without handicap) to the external world, became therefore a passport to an 'elite' class, to further raise chauvinistic arguments against English for the masses. Irrelevant examples of Russia, China and Japan were used to deny this basic learning among the masses. Since the opening up, its value (in a competency sense, not as symbol) has gone up greatly. States like West Bengal and Maharashtra have revised their earlier policies and the latter has gone forward and made English education compulsory in primary school. The metro cities' continued extreme dominance in control, decision making, and most important to our discussion in the provision of exportable services (software, "offshoring" businesses, other services), is in part due to the fact that these cities were able to continue with their pre and early independence facilities in english language education. The rise of Pune, Bangalore and some of other southern centres and the export of surplus soft and white collar skills is in part due to moderation in these states' attempts to displace English.

\section{CONCLUSIONS}

Gujarat has attracted more FDI than the rest of the country, and in this respect it is a leader. But relative to its peer states (especially Tamilnadu, Delhi, Maharashtra and Karnataka, and possibly Andhra Pradesh) it has fallen short significantly.

While part of the reason for this shortfall is its industry mix - being much more in chemical and allied industries and in small scale manufacturing. Even adjusting for these industry differences, relative to its peers, it was able to attract significantly less FDI. This, as also the fact that high growth industries such as IT manufacturing and software and related industries has not only not taken root but early successes proved abortive is worrying. 
The above findings were confirmed in a survey of top managers and others intimately concerned with the foreign investment decision process.

The survey also elicited the important factors that determine the locational choice (regions of location) of foreign direct investments. The factors specific to particular industries apart, the general factors confirm the importance of the city and the living conditions therein. The survey also brings out the crucial importance of infrastructure, and the quality of governance both in the economic, and in the core functions (maintenance of law and order including the avoidance of communal strife) of government

Factors that have adversely affected Gujarat include the electricity supply its poor quality, inadequacy and high price; the adverse law and order situation including the impact of the communal strife and riots, and the perception of biases in the implementation of law.

In manufacturing there cannot be success without coordination with the central government, because many of the difficulties in moving forward and in evolving into second generation industries faced by Gujarat's manufacturing, both existing and potential new units, arise out of policy infirmities at the central /macroeconomic level. Important among these are the 'inverted tariff structures' that many of Gujarat's manufacturing, especially those in the small and medium scale industries, face; and the tame pricing of the Indian rupee. The latter is in sharp contrast to East Asian countries' strategy of undervaluing their currencies. The resulting discrimination against comparative advantage industries like textiles, chemicals, small parts manufacturing, light engineering is severe. That discrimination hurts Gujarat more than other states, because so much of its comparative advantage is in manufacturing especially small scale, downstream applications of petrochemicals and chemicals. Additionally, the much awaited reform of the small firm sector hurts Gujarat's manufacturing and the upgradation and modernisation of its small firm sector, since the interfirm linkages through FDI and other non-equity forms which need to develop are arrested.

Unless the state responds on a wise variety of fronts it is most likely to miss the important biotechnology revolution that would soon begin in the country. 


\section{Bibliography}

Aharoni, V. (1967), “The Foreign Investment Decision Process," Harvard, Mass., Harvard University Press.

Morris, Sebastian (2004), "A Study of the Regional Determinants of Foreign Direct Investments in India, and the Case of Gujarat", Working Paper No.2004/03/07, Indian Institute of Management, Ahmedabad.

Hymer, Stephen (1971), “The Multinational Corporation and the International Division of Labour", Chapter 6 in The Multinational Corporation: A Radical Approach, papers by Stephen Hymer, (ed.) by Cohen et al, Cambridge University Press, 1979.

Morris, S., Rakesh Basant, Keshab Das, Kavil Ramachandran, and Abraham Koshy (2001), "Growth and Transformation of Small Firms in India", New Delhi, Oxford University Press.

Morris, S., and Rakesh Basant (2004), "Role of Small Scale Industries in the Age of Liberalisation", Paper for the Second Technical Workshop of the Policy Group on Trade and Industry of the Asian Development Bank,

Morris, Sebastian (1997), Why not Push for a 9 Per Cent Growth Rate?, Economic and Political Weekly, May 17-24, pp.1153-1165.

Rosario, Shirley Louis (1998), "Emerging Patterns of Transnational Activity in India: A Study of Foreign Collaboration Intentions in the 1990s in India", Indian Institute of Management, doctoral dissertation (Fellow Programme in Management), IIMA, Ahmedabad.

September 2004, January 2005.

Ahmedabad 
Table 1: Results of Regression of the No. of Cases of Foreign Collaboration (Technical, and Technical Cum Financial) over Certain State Dummies and Other Variables

\begin{tabular}{lrrr}
\hline Variable & Coefficient & t-value & Sig.level \\
Constant & -14.1488 & -1.5692 & 0.1173 \\
Industry Dummies (39) & - & - & - \\
AP (D) & 11.52772 & 1.7257 & 0.0851 \\
Delhi (D) & 47.5953 & 7.5009 & 0.0000 \\
Gujarat (D) & 2.3853 & 0.3190 & 0.7499 \\
Karnataka (D) & 35.5202 & 5.8949 & 0.0000 \\
Maharashtra (D) & 39.6691 & 4.6151 & 0.0000 \\
Tamilnadu (D) & 29.0166 & 4.7086 & 0.0000 \\
SDP93 & 0.0000 & 2.7733 & 0.0058 \\
Log(SDP96/SDP93) & 11.0861 & 0.4795 & 0.6318 \\
R2 adjusted & & & 0.3873 \\
R2 & & & 0.4495 \\
No of Obs. & & & 474 \\
F-ratio & & & 7.2298 \\
\hline
\end{tabular}

Table 2: Results of Regression of the Foreign Equity in Foreign Collaboration (Technical Cum Financial) over Certain State Dummies and Other Variables

\begin{tabular}{lrrr}
\hline Variable & Coefficient & t-value & Sig.level \\
Constant & -281.488 & -1.3826 & 0.1676 \\
Industry Dummies (39) & - & - & - \\
AP (D) & 237.861 & 1.5766 & 0.1156 \\
Delhi (D) & 362.715 & 2.5309 & 0.0117 \\
Gujarat (D) & 253.349 & 1.5000 & 0.1343 \\
Karnataka (D) & 424.602 & 3.1200 & 0.0019 \\
Maharashtra (D) & 606.187 & 3.1225 & 0.0019 \\
Tamilnadu (D) & 351.444 & 2.5230 & 0.0019 \\
SDP93 & 0.000 & 1.7467 & 0.0814 \\
Log(SDP96/SDP93) & 181.242 & 0.3471 & 0.7287 \\
R2 adjusted & & & 0.1947 \\
R2 & & & 0.2765 \\
No of Obs. & & & 474 \\
F-ratio & & & 3.3829 \\
\hline
\end{tabular}


Table 3: Relative Average Rating of States on their FDI Potential and Achievement

\begin{tabular}{|c|c|c|c|c|c|c|c|c|c|c|}
\hline & \multicolumn{5}{|c|}{ Potential for FDI } & \multicolumn{5}{|c|}{ "Performance" on FDI } \\
\hline & No & Min & Max. & Mean & Std.Dev. & No & Min & Max. & Mean & Std.Dev \\
\hline $\begin{array}{l}\text { Maharastr } \\
\text { a }\end{array}$ & 70 & 50 & 100 & 78.5 & 11.71 & 70 & 10 & 90 & 67.5 & 15.19 \\
\hline Karnataka & 70 & 8 & 100 & 75.9 & 14.98 & 68 & 30 & 100 & 65.1 & 15.43 \\
\hline Tamilnadu & 71 & 40 & 100 & 74.4 & 13.08 & 71 & 30 & 100 & 63.6 & 16.16 \\
\hline Gujarat & 69 & 25 & 100 & 73.5 & 15.09 & 70 & 30 & 90 & 63.6 & 14.79 \\
\hline $\begin{array}{l}\text { Andhra } \\
\text { Pradesh }\end{array}$ & 69 & 35 & 100 & 73.4 & 11.54 & 68 & 10 & 94 & 52.9 & 19.15 \\
\hline $\begin{array}{l}\text { Uttar } \\
\text { Pradesh }\end{array}$ & 66 & 10 & 90 & 52.5 & 18.44 & 65 & 5 & 80 & 38.8 & 17.79 \\
\hline $\begin{array}{l}\text { West } \\
\text { Bengal }\end{array}$ & 67 & 10 & 90 & 51.3 & 16.45 & 65 & 0 & 80 & 37.4 & 19.08 \\
\hline Orissa & 65 & 5 & 85 & 45.3 & 18.64 & 61 & 0 & 70 & 33.3 & 21.57 \\
\hline
\end{tabular}

Table 5: Ratio of "Achievement" to Potential with Regard to Inward FDI.

\begin{tabular}{lrrrrr}
\hline & No. & Minimum & Maximum & Mean & Std. Deviation \\
\hline Maharastra & 70 & 0.44 & 1.33 & 0.81 & 0.17 \\
Karnataka & 70 & 0.10 & 8.13 & 0.99 & 0.88 \\
Tamilnadu & 71 & 0.44 & 1.33 & 0.86 & 0.18 \\
Gujarat & 68 & 0.25 & 1.33 & 0.71 & 0.21 \\
Andhra Pradesh & 68 & 0.50 & 1.40 & 0.89 & 0.20 \\
Uttar Pradesh & 65 & 0.00 & 1.50 & 0.71 & 0.30 \\
West Bengal & 65 & 0.32 & 1.40 & 0.74 & 0.28 \\
Orissa & 61 & 0.00 & 1.75 & 0.68 & 0.38 \\
\hline
\end{tabular}


Table 4: Standardised Scores for the FDI Potential and FDI Achievement Across States

\begin{tabular}{lrrrr}
\hline State & $\begin{array}{r}\text { No. of } \\
\text { respondents }\end{array}$ & "Potential" & $\begin{array}{r}\text { No. of } \\
\text { respondents }\end{array}$ & "Achievement" \\
\hline Maharashtra & 70 & 0.7896 & 70 & 0.5784 \\
Karnataka & 70 & 0.6380 & 70 & 0.5838 \\
Tamilnadu & 71 & 0.4643 & 71 & 0.5721 \\
Gujarat & 69 & 0.4309 & 68 & -0.0600 \\
Andhra & 69 & 0.3987 & 68 & 0.6122 \\
Pradesh & & & & \\
Uttar Pradesh & 66 & -0.8004 & 65 & -0.8563 \\
West Bengal & 67 & -0.8710 & 65 & -0.7628 \\
Orissa & 65 & -1.2084 & 61 & -1.0829 \\
\hline
\end{tabular}

NB: Scores are standardised values of the marks awarded out of 100 with mean zero and standard deviation 1.

Table 6: Performance of Gujarat in Attracting FDI During the Last Several Year (Approx. from 1997): Distribution of Responses over Different Categories of Performance

\begin{tabular}{lrr}
\hline Response Category & No. of respondents & Per cent to total \\
\hline Below potential & 55 & 74.3 \\
At its potential & 11 & 14.9 \\
Above its potential & 1 & 1.4 \\
Can not say & 2 & 2.7 \\
Missing & 4 & 5.4 \\
\hline All response & 74 & 100.0 \\
\hline
\end{tabular}

Table 7: Performance of Gujarat in Attracting FDI During the Last Several Year (Approx. from 1997) Relative to Other States in the Set - Distribution of Responses over Different Categories of Performance

\begin{tabular}{lrr}
\hline Response Category & No. of respondents & Per cent to total \\
\hline Below average & 32 & 43.2 \\
Average & 24 & 32.4 \\
Above average & 12 & 16.2 \\
Can not say & 2 & 2.7 \\
Missing & 4 & 5.4 \\
\hline All response & 74 & 100.0 \\
\hline
\end{tabular}


Table 8: Explanation for Gujarat's Relative Performance (Open Ended

\begin{tabular}{llrrr}
\multicolumn{5}{c}{ Responses) } \\
\hline S.No.
\end{tabular}

NB: Figures in brackets are number of respondents in each set. 
Table 9:Opinion Regarding the Desirability of FDI

\begin{tabular}{llllll}
\hline & Yes & No & $\begin{array}{l}\text { Cannot } \\
\text { say }\end{array}$ & All \\
\hline $\begin{array}{l}\text { Would low achievement of FDI (relative) to its potential } \\
\text { be undesirable from the standpoint of the regions }\end{array}$ & 58 & 11 & 5 & 74 \\
$\begin{array}{l}\text { economic development? } \\
\begin{array}{l}\text { Would low achievement of a state in FDI be undesirable } \\
\text { from the standpoint of its economic development even if }\end{array}\end{array}$ & & & & & \\
$\begin{array}{l}\text { it has performed well in attracting investments } \\
\text { (especially from local and national firms)? }\end{array}$ & & & & 74 \\
\hline
\end{tabular}


Table 10: Rating of Various City Level /Living Factors in Influencing the Locational Choice of Foreign Direct Investments

\begin{tabular}{|c|c|c|c|c|c|}
\hline \multirow[t]{2}{*}{ City /Living Factors } & \multirow[b]{2}{*}{$\begin{array}{r}\text { No. of } \\
\text { Respndents }\end{array}$} & \multicolumn{2}{|c|}{ Scores } & \multicolumn{2}{|c|}{$\begin{array}{l}\text { Scores normalised } \\
\text { across all responses of } \\
\text { the respondent }\end{array}$} \\
\hline & & Mean & $\begin{array}{r}\text { Std.De } \\
\text { v. }\end{array}$ & Mean & Std.Dev \\
\hline $\begin{array}{l}\text { 4. Safety freedom from crime } \\
\text { law and order in the city }\end{array}$ & 74 & 6.15 & 1.04 & 0.97 & 0.65 \\
\hline $\begin{array}{l}\text { 15. Reliability of electricity } \\
\text { supply in the city }\end{array}$ & 74 & 6.05 & 1.06 & 0.87 & 0.69 \\
\hline 20. Clean drinking water & 74 & 5.97 & 1.02 & 0.78 & 0.69 \\
\hline 23. Good health care facilities & 74 & 5.74 & 1.07 & 0.58 & 0.67 \\
\hline $\begin{array}{l}\text { 13. Quality hospital and } \\
\text { medical services in the city }\end{array}$ & 73 & 5.62 & 1.13 & 0.54 & 0.64 \\
\hline $\begin{array}{l}\text { 11. Quality of life possible in the } \\
\text { city }\end{array}$ & 74 & 5.45 & 1.04 & 0.39 & 0.67 \\
\hline 3. Pollution levels in the city & 73 & 5.33 & 1.18 & 0.25 & 0.94 \\
\hline $\begin{array}{l}\text { 12. Quality of schooling and } \\
\text { educational facilities }\end{array}$ & 74 & 5.23 & 1.08 & 0.21 & 0.63 \\
\hline 9. Quality of hotels & 73 & 5.08 & 1.10 & 0.15 & 0.61 \\
\hline $\begin{array}{l}\text { 6. Availability of quality real } \\
\text { estate }\end{array}$ & 72 & 5.04 & 1.11 & 0.05 & 0.77 \\
\hline $\begin{array}{l}\text { 7. Connectedness with city of } \\
\text { origin of foreign firm }\end{array}$ & 74 & 5.04 & 1.56 & 0.15 & 0.90 \\
\hline 1. Cleanliness of the city & 74 & 4.93 & 1.37 & -0.05 & 0.95 \\
\hline $\begin{array}{l}\text { 21. Availability of recreational } \\
\text { facilities }\end{array}$ & 74 & 4.93 & 1.22 & -0.02 & 0.74 \\
\hline 22. Cosmopolitan culture & 74 & 4.91 & 1.41 & 0.00 & 0.86 \\
\hline 5. International Quality & 74 & 4.76 & 1.42 & -0.12 & 0.74 \\
\hline Conference and Events Facilities & & & & & \\
\hline 10. Reliable public transport & 74 & 4.69 & 1.32 & -0.24 & 0.92 \\
\hline 14. Price of real estate in the city & 73 & 4.60 & 1.42 & -0.30 & 1.06 \\
\hline $\begin{array}{l}\text { 8. Existence of international } \\
\text { schools }\end{array}$ & 73 & 4.33 & 1.54 & -0.48 & 0.92 \\
\hline $\begin{array}{l}\text { 19. Modern shopping including } \\
\text { supermarkets / malls }\end{array}$ & 74 & 4.18 & 1.28 & -0.60 & 0.61 \\
\hline 16. Bracing climate & 72 & 4.01 & 1.52 & -0.70 & 1.06 \\
\hline 17. Metropolitan status & 73 & 3.99 & 1.58 & -0.72 & 0.91 \\
\hline $\begin{array}{l}\text { 18. Flexible building and } \\
\text { construction norms }\end{array}$ & 72 & 3.93 & 1.54 & -0.80 & 0.91 \\
\hline $\begin{array}{l}2 . \text { Significant presence of } \\
\text { expatriates }\end{array}$ & 74 & 3.76 & 1.51 & -0.98 & 1.09 \\
\hline
\end{tabular}

NB: Scores are standardised with mean zero and standard duration 1. 
Table 11: Rating of Various State Level Factors in Influencing the Locational Choice of Foreign Direct Investments

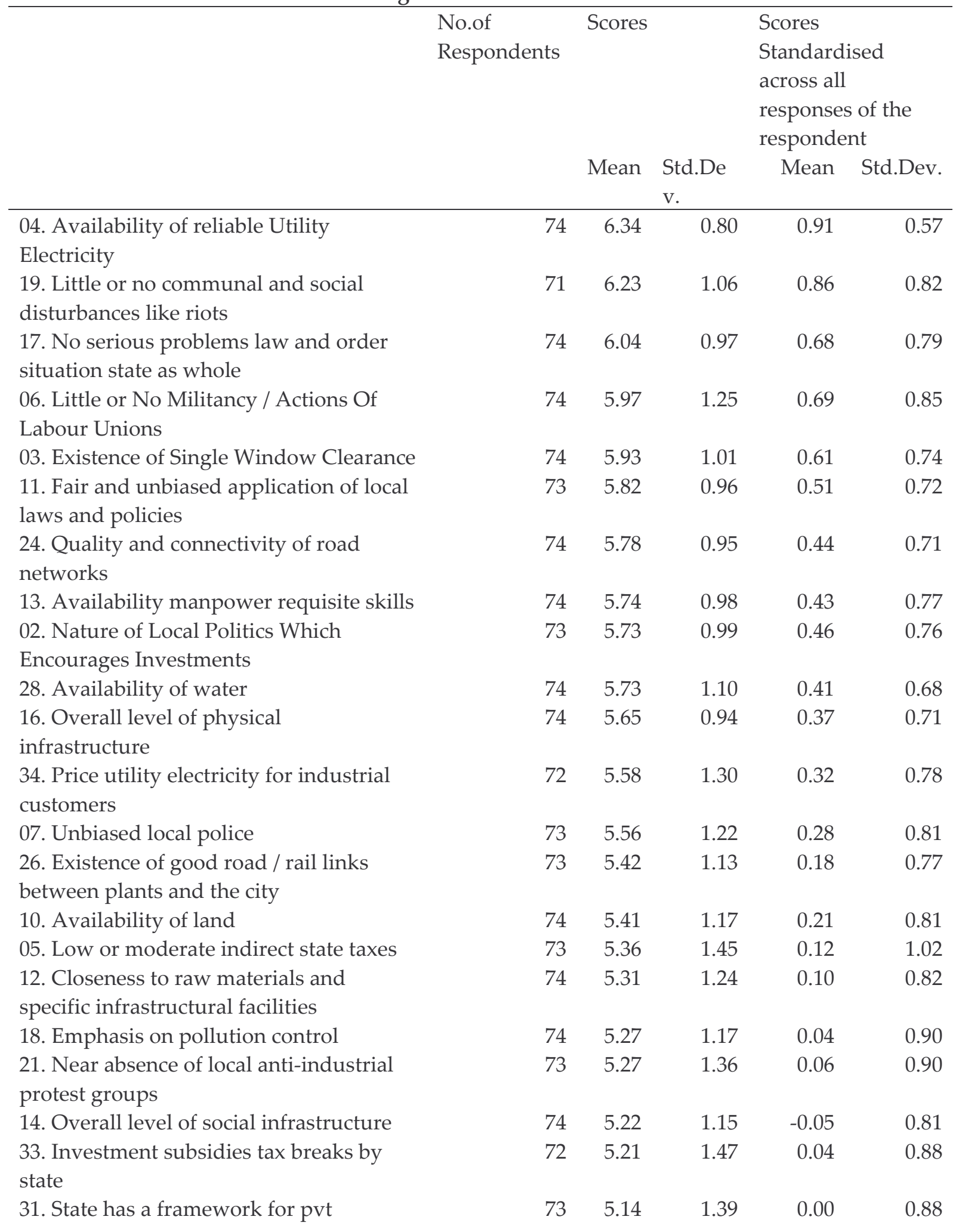


investment in infrastructure such as bot

09. Commitment of administration to

attracting local investments

32. Efficiency of state level judiciary

23. Reasonably low prices for land

35. Initiative shown by the investment

promotion agencies

20. Connectivity by rail networks

22. Rational location of industrial estates

wherein industries are allowed

27. Existence of container ports in the state

30. Prior industrialisation of the state

40. Absence of prohibition laws

25. Existence of sea ports in the state

38. Cost of unskilled and semi skilled

labour

37. Existence of agglomeration economies

in the place of location

01 . Tolerance of industrial pollution

39. Existence of SEZs in the state

15. Existence of planned info parks,

specialist high tech industry parks

36. State has cosmopolitan cities

41. Presence of export zones / agri

processing zones

29. State has cities of metropolitan status

08. Existence of large demand from

existing industries or from state

\begin{tabular}{lllll}
74 & 5.12 & 1.39 & 0.00 & 0.89 \\
74 & 5.12 & 1.38 & -0.06 & 1.00 \\
73 & 5.07 & 1.15 & -0.14 & 0.77 \\
72 & 5.07 & 1.36 & -0.09 & 0.93 \\
& & & & \\
73 & 4.92 & 1.35 & -0.21 & 0.86 \\
73 & 4.86 & 1.08 & -0.32 & 0.67 \\
& & & & \\
73 & 4.85 & 1.53 & -0.25 & 0.95 \\
& & & & \\
73 & 4.82 & 1.13 & -0.29 & 0.82 \\
74 & 4.80 & 1.64 & -0.40 & 1.30 \\
74 & 4.77 & 1.65 & -0.36 & 1.04 \\
73 & 4.60 & 1.47 & -0.45 & 1.01 \\
& & & & \\
72 & 4.53 & 1.33 & -0.51 & 0.78 \\
& & & & \\
71 & 4.49 & 1.79 & -0.59 & 1.24 \\
74 & 4.43 & 1.59 & -0.56 & 0.95 \\
73 & 4.34 & 1.67 & -0.65 & 0.94 \\
& & & & \\
73 & 4.34 & 1.33 & -0.67 & 0.91 \\
73 & 4.32 & 1.59 & -0.69 & 1.01 \\
& & & & \\
72 & 4.29 & 1.36 & -0.74 & 0.91 \\
74 & 4.19 & 1.75 & -0.75 & 1.20 \\
& & & & \\
\hline & & & &
\end{tabular}

NB: Scores are standardised to mean zero and variance 1. 
Table 12: A Comparison of Quantum of Technical Education Across Certain States in India

\begin{tabular}{lrrrr}
\hline State & $\begin{array}{r}\text { No of } \\
\text { Institutio } \\
\mathrm{ns}\end{array}$ & $\begin{array}{r}\text { Total no of } \\
\text { seats }\end{array}$ & $\begin{array}{r}\text { Population } \\
\text { c.2001 }\end{array}$ & $\begin{array}{r}\text { Seats per } \\
\text { thousand } \\
\text { population }\end{array}$ \\
\hline Andhra Pradesh & 527 & 54516 & 75727541 & 72.0 \\
Delhi & 93 & 14634 & 13782976 & 106.2 \\
Gujarat & 120 & 18490 & 50596992 & 36.5 \\
Karnataka & 551 & 76723 & 52733958 & 145.5 \\
Maharashtra & 608 & 92147 & 96752247 & 95.2 \\
Orissa & 129 & 14363 & 36706920 & 39.1 \\
Tamilnadu & 695 & 99364 & 62110839 & 160.0 \\
Uttar Pradesh & 364 & 37493 & 166052859 & 22.6 \\
West Bengal & 105 & 14262 & 80221171 & 17.8 \\
\hline India & 3993 & 520403 & $1.027 \mathrm{E}+09$ & 50.7 \\
\hline Source: Seats & & & & \\
\hline
\end{tabular}

Source: Seats and no of Institutions from AICTE as reported by Rockford

Foundation on their website; Population from Census of India 2001, Director General of Census. 
Table 13: Responses to the Question "What can Gujarat do to attract more FDI?" Categorised by the Performance Rating of Gujarat in Attracting FDI

\begin{tabular}{|c|c|c|c|c|c|c|}
\hline \multirow[t]{2}{*}{ Aspect /Issue } & \multicolumn{3}{|c|}{ Relative to peers } & \multicolumn{3}{|c|}{ Relative to potential } \\
\hline & $\begin{array}{r}\text { Below } \\
\text { average } \\
\text { or } \\
\text { average }\end{array}$ & $\begin{array}{l}\text { Above } \\
\text { average }\end{array}$ & All & $\begin{array}{r}\text { Below } \\
\text { or at } \\
\text { potenti } \\
\text { al }\end{array}$ & $\begin{array}{r}\text { Above } \\
\text { potential }\end{array}$ & All \\
\hline $\begin{array}{l}\text { Improving infrastructure services } \\
\text { and their pricing }\end{array}$ & 46 & 11 & 57 & 57 & 0 & 57 \\
\hline $\begin{array}{l}\text { Decision making, working of the } \\
\text { bureaucracy and economic } \\
\text { governance }\end{array}$ & 38 & 5 & 43 & 43 & 0 & 43 \\
\hline $\begin{array}{l}\text { Improving living conditions (incl. } \\
\text { physical and social } \\
\text { infrastructure) especially in the } \\
\text { city }\end{array}$ & 16 & 7 & 23 & 23 & 0 & 23 \\
\hline $\begin{array}{l}\text { Improving the law and order and } \\
\text { the core governance aspects of } \\
\text { the state, including avoidance/ } \\
\text { control of communal situation } \\
\text { /riots }\end{array}$ & 16 & 5 & 21 & 21 & 0 & 21 \\
\hline $\begin{array}{l}\text { Image of the state (incl. in the } \\
\text { mass media) needs change }\end{array}$ & 13 & 2 & 15 & 13 & 0 & 13 \\
\hline $\begin{array}{l}\text { Improving the availability and } \\
\text { pricing of factors of production }\end{array}$ & 9 & 3 & 12 & 12 & 0 & 12 \\
\hline $\begin{array}{l}\text { Policy corrections and changes } \\
\text { are required }\end{array}$ & 9 & 3 & 12 & 12 & 0 & 12 \\
\hline $\begin{array}{l}\text { Political propensities, behaviour } \\
\text { and concerns }\end{array}$ & 9 & 1 & 10 & 10 & 0 & 10 \\
\hline $\begin{array}{l}\text { Prior development, building } \\
\text { upon and exploiting }\end{array}$ & 2 & 0 & 2 & 2 & 0 & 2 \\
\hline
\end{tabular}




\title{
Appendix 1: Openended Responses to "What Factors Explain the Relative Performance of Gujarat?"
}

\author{
Statements Showing Improvements are Possible \\ A negative approach of the bureaucracy, \\ Inability to root out corruption at various \\ levels \\ A rigid approach to issues and \\ unwillingness to look at the industry's \\ perspective \\ Absence of a metropolis has aggravated \\ this problem \\ Absence of any proactive strategy from \\ the government to attract investment - \\ consistency \\ Absence of communal harmony \\ Adverse publicity by media \\ Also the $\mathrm{CM}$ and government have to \\ proactively market the state \\ Apprehension of personal safety in view \\ of recent communal riots \\ Availability of raw materials for \\ infrastructural units like steel, cements etc. \\ Civil unrest (poor law and order situation) \\ Communal disharmony \\ Communal disturbances in Gujarat have \\ created a question in the minds of the \\ investors \\ Communal problems \\ Communal violence in the state puts a \\ question mark on the stability of the new \\ proposals \\ Communal violence/disturbance \\ Communally sensitive \\ Corrupt administration \\ Decision making and implementation \\ Dependence on a few core sectors \\ e.g.refineries \\ Earth quake impact \\ Education \\ English language \\ Ethnic strife and communal disharmony \\ Exposure not adequately portrayed. \\ Fear of product design patents being \\ violated by local competitors \\ Few natural reasons to make investments \\ in Gujarat in terms of raw materials \\ Frequent religious unrest and strife \\ Further Gujarat has not been able to \\ project itself as a forward looking state \\ like Karnataka and AP \\ Geographical location (seismic zone- \\ earthquakes), \\ Govt policies on prohibition is also \\ another deterrent. Gujarat is communally \\ sensitive state \\ Gujarat is being perceived as below \\ acceptable in infrastructure, airports roads \\ etc \\ Gujarat is perceived as a parochial state \\ Gujarat performance in \\ secular/democratic norms is below \\ expectations \\ Gujarat pollution levels are high \\ Gujarat still lacks international appeal \\ Has not given enough importance to IT \\ and services sector \\ High handed political leadership \\ High levels of corruption \\ Higher power cost \\ Ill planned, poorly maintained cities, \\ towns \\ Illegal proliferation of BT cotton in \\ Gujarat has made it impossible for seed \\ and biotech companies to think of Gujarat \\ Illiteracy may also be a deterrent factor, \\ Business integrity, honesty, transparency \\ may be a doubted factor,
}


Image of the state. marketing Gujarat as destination for investment, social security/political stability In hospitality services taxes play an important role. The state taxes on the industries is the -

Inadequate availability of professional manpower

Inadequate infrastructure - power generation - electricity, water, roads, flexible labour policy etc

Inadequate power/electricity to industrial units

Increased communal disharmony

Infrastructure

Infrastructure

Infrastructure - power (too expensive)

Infrastructure (basic) facilities

Infrastructure and facilities need to be upgraded in industrial zones

Infrastructure development

Infrastructure needs improvement

Insufficient Infrastructure

Insufficient skilled manpower

Internal law and order situation

International standard of infrastructure

It should drop anachronism like

prohibition and ensure law and order

Lack of brand equity and visibility -

relative to other states

Lack of cosmopolitan culture in large

cities

Lack of focus, visibility - as an attractive

FDI destination

Lack of good incentives/tax benefits against other states

Lack of good infrastructure, power, social

security, subsidies/benefits

Lack of government focus to attract FDI

Lack of ICT education

Lack of industrial infrastructure in and

around main cities e.g. skilled labour, townships, ancillary units, roads, communication links etc.

Lack of infrastructure as to ports, international airports etc.

Lack of international airports
Lack of IT infrastructure

Lack of large markets within Gujarat

Lack of local initiative to hard sell the opportunities

Lack of policy changes to adjust to changing social values such as "prohibition"

Lack of political support from centre

Language and social infrastructural problems

Law and order problems

Law and order situation

Liberalisation may not have been fully

projected

Low visibility

Lower facilitation of newer growth industries like pharma, technology etc Most multinationals still look at Gujarat negatively given the communal issues Needs more focus on infrastructure development

No serious efforts made to attract investments. There are a few large players like Reliance who make up for most of the investment

No USP: in respect to skilled manpower, innovation Govt support, crisis related to power, water and other infrastructure Non-availability of cheap labour NRI's of Gujarati origin may not be tapped properly Partisan attitude of state administration Perception of a disturbed social and communal environment.

Perception of global investors towards Gujarat as a state not safe and having communal overtones

Perception of Gujarat as a communally sensitive state Political and cultural climate resulting in uneasiness amongst investors

Political and social issues

Political climate

Political Impact

Political influence (Negative)

Political Instability

Political instability 
Political situation

Political situation

Political status

Political uncertainty, lack of focussed

approach

Politically extreme

Politically not being projected properly by

its chief minister to attract FDI

Poor educational standard and no good

facilities for outsiders, forget overseas

investors

Poor governance

Poor infrastructure

Poor infrastructure in areas where raw materials are pursued - viz oil in the

Mehsana Area

Poor infrastructure, educational facilities

Poor infrastructure, high cost of power,

Shabby cities and towns and

Poor knowledge of english

Power cost in Gujarat is by far the highest

in India and this is a great deterrent for growth.

Power is deterrent factor.

Power tariffs are also the highest

Proactive approach

Problem in Gujarat are high cost of power

and labour laws which will have to be

more industry favourable.

Prohibition policy does not attract

investments/travellers

\section{Appreciative Statements}

Adequate power, roads, transport

infrastructure

Attractive FDI destination.

Availability of better infrastructural

facilities, good connectivity with other

states by rail, road and air

Big names like Reliance, GAIL, Essar

group have set up plant there.

Closeness to port \& already having good

amount of FDI

Compensative liberal approach of

Government'sdesire to do well
Quality of educational infrastructure

including English

Recent commercial tensions/political uncertainty

Recently, bad publicity as a result of religious violence

Relative to its peer group, low emphasis

by the Government on

marketing/promoting the state

Simplification of procedure for FDI.

Skilled labour shortages. Communications

(lack of multilingual skills, most of the

people speak Gujarati)

Social disturbance

Social harmony

Social infrastructure not up to the mark as

in rest of the metros to attract top ranking

talent

Social tensions/riots

Talent availability is an issue in relative

terms. Language barrier (English) needs to

be dealt with

Tech skills, labour situation

Uncertainties post Gujarat riots

Unclear investment policies

Unstable social structure. Riots/militancy

at regular intervals

Utilities, water

Weak infrastructure
Enterprising Gujarati's citizens and docile

- labour

Excellent port facility, road and

infrastructure

Existence of a large existing industrial

base.

Existing locations of Indian partners of foreign JV.

Fact that Gujarati's are mainly a business

community has helped a lot. Business has

always flourished in Gujarat.

Focus of the government in power

Friendly and positive industrial climate 
Friendly.

Good governance, investor friendly

Good law \& order situation except some aberration.

Good roads and well developed ports

Government has been proactive in some areas

Government policies / bureaucracy

Growth

Gujarat's coastline

Gujarat has a good industrial climate, infrastructure facilities and peaceful

labour.

Gujarat has to be shown up to the investors as an attractive FDI destination. Gujarat has very good environment for investments due to its people who are oriented towards business Gujarat is close to Mumbai and has always been well industrialized. The state government has encouraged enterprise. Gujarat state has pro business leanings In comparison with other states, things get done even in government offices

Industrial cluster e.g. Ankleshwar

Industrially developed state

Infrastructure

Investor friendly - relatively - Government

Large body of NRI investors

Local support

Mix culture allowing outsiders to get

involved

Proximity to seaport,

Availability of skilled labour and

manpower

Reasonable infrastructure

Relatively business friendly reputation of bureaucracy

Relatively peaceful (except last two years)

Road and transport infrastructure,

Modern port facility and management

Safe and peaceful environment/climate

Safety, law and order

Sensible state government

Stable political atmosphere

Strong infrastructure
Textile, gem \& jewellery \& more Indian industrial/commercial occupations will be asset to attract

Communal situation

Trade/business oriented approach of people

With Ahmedabad, Baroda and Surat being centres of business.

It has also has good ports and overall is suited for enterprise 
Appendix 2: Categorised Open Ended Responses on the Reasons for the Underperformance of Gujarat, of those who had Opined that Gujarat has Underperformed in FDI Relative to its Potential.

\begin{tabular}{lr}
\hline Issue / Reason ** & $\begin{array}{r}\text { No of } \\
\text { Respondents }\end{array}$ \\
& * \\
\hline RS16 Infrastructure general & 22 \\
RS19 Law and order /communal situation /riot & 18
\end{tabular}

management

RS35 Decision making investment promotion 13

RO1 Image of the state 8

RS11 Decision making decision $\quad 7$

RS13 Factor manpower $\quad 7$

RS17 Law and order general $\quad 7$

RS30 Development prior industrialization $\quad 7$

RS9 Decision making commitment 6

RS25 Infrastructure port 6

RO7 Stable govt 6

RC12 Living education $\quad 5$

RS21 Politics environment 5

RS34 Infrastructure power price 5

RO5 English language ability of people 5

RS4 Infrastructure power 4

RS6 Politics labour 4

RS40 Policy prohibition $\quad 4$

RS33 Factor tax incentives 3

RC1 Living clean $\quad 2$

RC17 Living metro $\quad 2$

RC22 Living culture $\quad 2$

RS2 Politics encourages Industry $\quad 2$

RS3 Decision making single Window 2

RS12 Factor raw materials or specific factors 2

RS15 Infrastructure special zones parks 2

RS18 Decision making pollution emphasis 2

RS24 Infrastructure road 2

RS28 Infrastructure water 2

RO8 Seismic zone $\quad 2$

RC7 Infrastructure air connectedness 1

RC21 Living recreation 1

RS5 Factor tax low 1

RS8 Factor demand Local 1

RS22 Infrastructure estates 1

RS37 Development agglomeration $\quad 1$

RS38 Factor manpower price 1

RO6 Central govt support $\quad 1$

RO9 IPR 1

${ }^{* *}$ Categories with no response are not listed; * There were 66

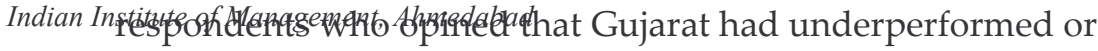

performed at its potential. 
Appendix 3: Open-ended Suggestions on What Gujarat Can do to Attract More FDI

Be more proactive to industry

Eliminate bureaucracy and corruption

Make industry feel wanted rather than present feeling of being unwanted

Excellent infrastructure, reliable uninterrupted power supply

Safety, peace and good law and order

Attractive financial incentives, flexible labour policies and industry-friendly, transparent governance

Set up few international airports - connected to east/west

Change the image of governance

Offer relatively better incentives/infrastructure

Focus on infrastructure

Flexible labour laws, tax relief incentives - electrical/water/subsidies, more

power/electricity/water for industrial establishments.

More transparency in government dealings

Improve the communal image, improve the infrastructure

Clean up the cities and towns and modernise them, Improve the IT climate

Create functioning industrial parks, Bring down the cost of power

Provide a stable and secular political climate

Develop it's markets to enable industries to locate themselves close to their consumers

Provide tax breaks

Ensure communal harmony

Improve infrastructure

Improve its image and offer a safe working environment

To educate young males/females to improve English speaking accent/proficiency

Make cities more clean/environment friendly and free from dust pollution

Further better education facilities at school and undergraduate level

SEZ and international quality infrastructure, roads, airports, Hotels, seminar facilities etc

Good publicity and image building exercise - currently media is negative

Political influence to get lion's share from centre

Image build up of investor friendly examples

Big ticket investments by local/foreign cos. by proactive efforts

Internal law and order situation

Specific promotional efforts

Infrastructural facilities (basic)

Improvement in facilities offered in Industrial Estates

Display a clean track record of law and order situation

Offer single window services for FDI with financial incentives

Have a transparent administration

Encourage investments and business focus \& without props \& supports

Have a world class infrastructure

Avoid aberration regarding law and communal harmony. Simplify prudence, single

window etc.

The special ministry like finance/industry etc to be handled by professionals.

Fast clearance of projects 


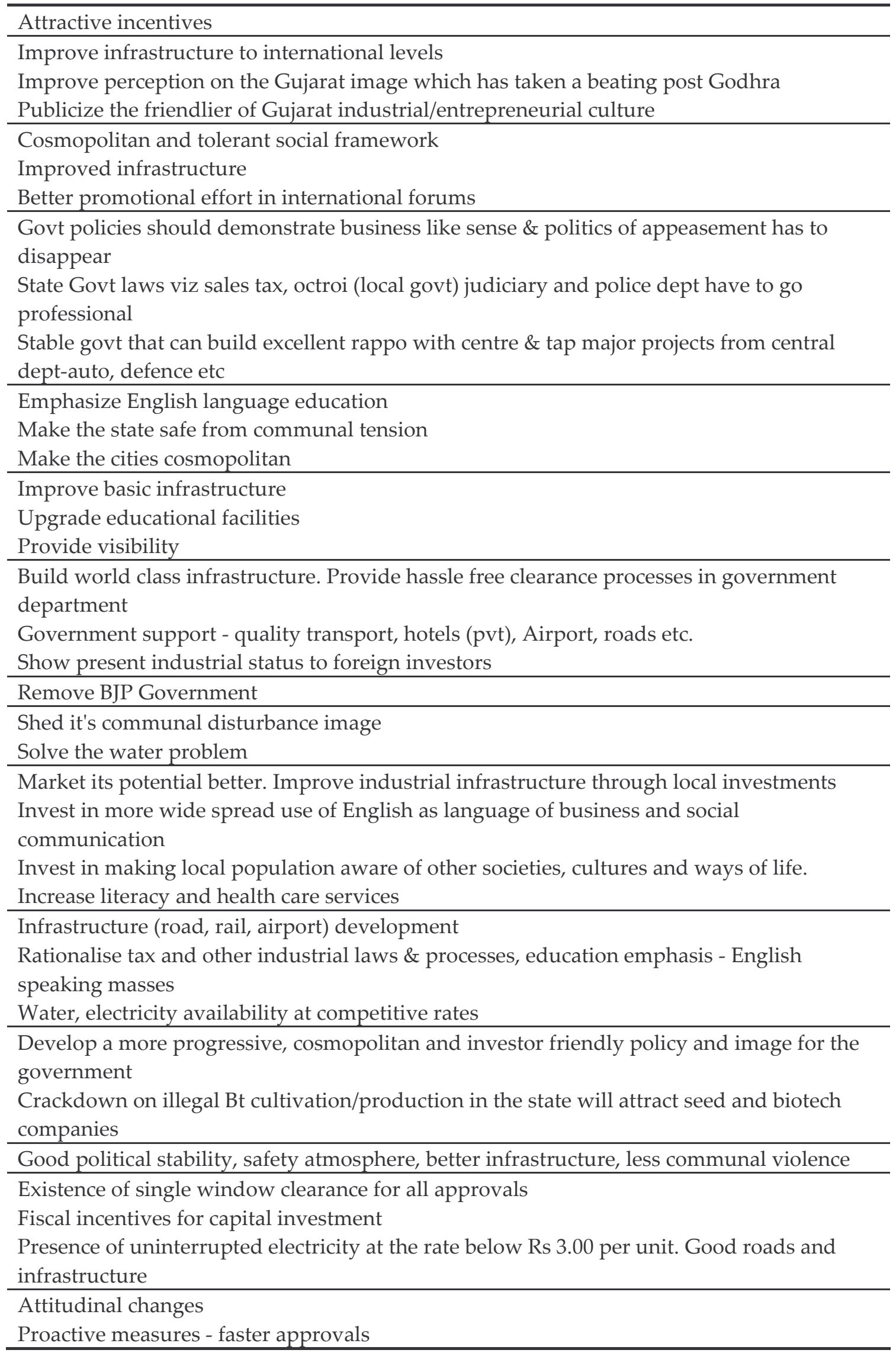


Consistent policy - approach to be transparent

Position yourself as forward thinking non-communal state

Build on world class infrastructure; control fiscal deficit, concentrate on rural development without

Fund leakage; increase tax compliance; market the state globally

Allow industry to "excel" do not indulge in the petty politics \& put uncompetitive compulsions

Do take state government responsibilities seriously and demonstrate that through actions

Develop educational infrastructure and improve quality

Evolve forward looking culture and attitudes rather than harping on tradition

Reduce communal friction/riots

Reduce power cost/tariff

Remove prohibitions orders

Explore the states strength as to the raw cotton production is the highest. Hence boost spinning/cloth and garment industry

Improve its image tarnished due to law and order problem

Improve connectivity by air, have a modern airport and good roads

Drop prohibition (to expect foreigner not to drink is a joke and permits are a way of corruption)

More politically limited to concern on international human rights

Avoiding riots and religious discrimination

Improvement of law and order

Infrastructure development

Efficient bureaucracy

Improve the confidence of industries in law and order

Political stability and proactive approach

Improve work culture of labour

Demonstrate that the post-Godhra riots is a freak incident and that it is not the norm of the

state through friendly attitude of the prospective and-

Present investors,

In the short terms Gujarat can provide stage sponsored subsidies for attracting new investments

Provide stability in governance, pro-active attitude towards FDI

Improve infrastructure such as roads, airports etc.

Improve educational facilities in professional courses

Availability of land with good rates, Sales tax etc benefits for initial period

Improvement in infrastructure

Rail and air connectivity, power availability

Attract international schools, provide better domestic and International flights

Abolish prohibition, avoid communalism

Provide better local government, cleaner cities, better rule enforcement at all levels

It should abolish the age old "prohibition" which carries no meaning. Infrastructure should be improved

Most of the towns in Gujarat are quite dirty. Cleaning them up will help a lot. Although Gujarat has a good deal of industries- it is not considered as a state which produces quality product especially in engineering. This image needs to be changed 
Implement and create a stable, secular political environment

Ensure law and order consistently

Prioritize domestic investment with corporate, industrial companies

Prioritize domestic investments already in JV, encourage them to expand in Gujarat, this

will attract other untested FDIs

Electric power supply must be constant \& most important factor. Gujarat business

community must have integrity/honesty in JV

Focus on "select industries" to maximise agglomeration effect

Power charges to be made competitive \& water availability improved. Road network

enlarged and improved

Relax laws on "prohibition"

Improve law and order situation

Give more tax breaks both direct \& indirect, Improving state level judiciary

Emphasis on pollution control

Create a better perception/awareness of advantages of the state (industrial base,

infrastructure, skilled manpower)

Create an enabling environment for expeditious decision making for clearances, land acquisition and absence of corruption/delay

Adequate power must be available at competitive prices and this must be in par with what is available in other parts of the country.

Labour laws must be more industry friendly

Improve quality of technical education, Improve quality of vocational training (ITIs)

Remove perception that Gujarat is a communally sensitive state through affirmative action, water available

Reduce pollution through strict implementation of pollution laws. Improve public

transport system

Bring about cosmopolitan culture in some key cities

Give assurances on safety, law and order and secularism

Develop ITES sector

Creation of world class infrastructure for transportation

Creation of port facility of international cargo handling

Provision of adequate water/electricity and check on pollution

Better law and order situation in the state

Better social and physical infrastructure

Industry friendly government

Create the political environment that will be much more cohesive

Giving a welcome feeling to interested investors

Stable government

Law \& Order

Cosmopolitan culture, lifting prohibition, good hotels etc.

Improve overall image - as a liberal

Progressive state focussed on economic development and a liberal policy regime

Increase water harvesting schemes

Give an international touch to its cities and towns

Remove communal bias and ease tension

Repair the existing negative image re: violence 
Focus on specific industry segments and promote

Make single window clearance really effective

Create specific zones for product specific industries

The local industrial giants should be taken into confidence along with political leaders of state to

Project the state as an infrastructure/investment friendly option

The communal blot on Gujarat has to subside. Actively this has to be pursued

Foreigners do not believe that what happened will not be repeated. The state government has to go out of its way to attract FDI.

A lesson can be learnt from the way Chandrababu Naidu marketed Andhra Pradesh

Clarity on various policies for the long term

Provide good infrastructure and consistent utility services like electricity water etc

Try to negate the perception among foreign investors of a communal state

Develop energy infrastructure

Promote manufacturing

Safe and peaceful environment/climate

Improve power, water, air quality, effluent treatment, road facilities in existing industrial estates

Enhance English, Hindi, language skills of all students in the state. Improve the conditions of all its cities \& towns - roads, sanitation, power, water, schools, recreation, sports, and public transport. Privatise state PSU's and focus on above, similar issues and SEB

Improve infrastructure

Improve political climate/cultural or religious bias

Have no communal clashes

To implement strict law and order in the state

Make politics independent of eco and commerce

Improve drastically all kind of transport, medical and education facility, water and

drainage management, electricity: basically infrastructural facility

Clean politics

Improve infrastructure

Change policies

Better social and economic environment 
Appendix 4: Categorised Open Ended Responses on “What Gujarat can do to attract more FDI", of those who had Opined that Gujarat has Underperformed in FDI Relative to its Potential

\begin{tabular}{|c|c|}
\hline Issue / Action or change category & No of responses \\
\hline GS16 infrastructure general & 28 \\
\hline GS35. Decision making / investment promotion & 20 \\
\hline GS19. Law and order related to communal problem /riots & 16 \\
\hline GO1. Image & 15 \\
\hline GS9. Decision making commitment & 11 \\
\hline GS3. Decision making / single window & 10 \\
\hline GS11. Decision making decision & 9 \\
\hline GS17. Law and order general & 8 \\
\hline GS28. Infrastructure water & 8 \\
\hline GS33. Factor tax incentives & 7 \\
\hline GC1. Living clean & 6 \\
\hline GC12. Living education & 6 \\
\hline GS4. Infrastructure power & 6 \\
\hline GS34. Infrastructure power price & 6 \\
\hline GS40. Policy prohibition & 6 \\
\hline GC22. Living culture & 5 \\
\hline GS2. Politics encourages Industry & 4 \\
\hline GO5. English & 4 \\
\hline GO7. Stable govt. & 4 \\
\hline GC7. Infrastructure air connectedness & 3 \\
\hline GS5. Factor tax low & 3 \\
\hline GS18. Decision making pollution emphasis & 3 \\
\hline GS13. Factor manpower & 2 \\
\hline GS22. Infrastructure estates & 2 \\
\hline GS30. Development industrialization & 2 \\
\hline GS32. Decision making judiciary & 2 \\
\hline GO4. Tax administration & 2 \\
\hline GO6. Central govt. support & 2 \\
\hline GC4. Law and order safety & 1 \\
\hline GC8. Living education international & 1 \\
\hline GC9. Living hotels & 1 \\
\hline GC10. Living transport & 1 \\
\hline GC13. Living health & 1 \\
\hline GC16. Living climate & 1 \\
\hline GC21. Living recreation & 1 \\
\hline GS6. Politics labour & 1 \\
\hline GS8. Factor demand local & 1 \\
\hline GS10. Infrastructure land & 1 \\
\hline GS14. Infrastructure social & 1 \\
\hline GS15. Infrastructure special zones parks & 1 \\
\hline GS21. Politics environment & 1 \\
\hline
\end{tabular}


GS23. Infrastructure land price 1

GS24. Infrastructure road 1

GS25. Infrastructure port 1

GS36. Living cosmopolitan 1

GS37. Development agglomeration 1

GS39. Policy zones 1

GO2. Fiscal deficit 1

GO3. Rural development 1

GC2. Living culture foreign presence 0

GC3. Living pollution 0

GC5. Infrastructure conference 0

GC6. Living real estate 0

GC11. Living quality in city 0

GC14. Living real estate price 0

GC15. Living power 0

GC17. Living metro 0

GC18. Building 0

GC19. Living shopping 0

GC20. Living water 0

GC23. Living health 0

GS1. Decision making pollution tolerance 0

GS7. Extension practice 0

GS12. Factor raw material special 0

GS20. Infrastructure rail 0

GS26. Infrastructure connection to city 0

GS27. Infrastructure container 0

GS29. Development metro 0

GS31. Policy BOT 0

GS38. Factor manpower price 0

GS41. Policy zones other 0

GO8. Seismic zone 0

GO9. IPR 0 